\title{
Variations in Respiratory Excretion of Carbon Dioxide Can Be Used to Calculate Pulmonary Blood Flow
}

\author{
David A. Preiss ${ }^{\text {a }}$, Takafumi Azami ${ }^{\text {b }}$, Richard D. Urman ${ }^{\mathrm{c}, \mathrm{d}}$
}

\begin{abstract}
Background: A non-invasive means of measuring pulmonary blood flow (PBF) would have numerous benefits in medicine. Traditionally, respiratory-based methods require breathing maneuvers, partial rebreathing, or foreign gas mixing because exhaled $\mathrm{CO}_{2}$ volume on a per-breath basis does not accurately represent alveolar exchange of $\mathrm{CO}_{2}$. We hypothesized that if the dilutional effect of the functional residual capacity was accounted for, the relationship between the calculated volume of $\mathrm{CO}_{2}$ removed per breath and the alveolar partial pressure of $\mathrm{CO}_{2}$ would be reversely linear.
\end{abstract}

Methods: A computer model was developed that uses variable tidal breathing to calculate $\mathrm{CO}_{2}$ removal per breath at the level of the alveoli. We iterated estimates for functional residual capacity to create the best linear fit of alveolar $\mathrm{CO}_{2}$ pressure and $\mathrm{CO}_{2}$ elimination for 10 minutes of breathing and incorporated the volume of $\mathrm{CO}_{2}$ elimination into the Fick equation to calculate PBF.

Results: The relationship between alveolar pressure of $\mathrm{CO}_{2}$ and $\mathrm{CO}_{2}$ elimination produced an $\mathrm{R}^{2}=0.83$. The optimal functional residual capacity differed from the "actual" capacity by $0.25 \mathrm{~L}(8.3 \%)$. The repeatability coefficient leveled at 0.09 at 10 breaths and the difference between the PBF calculated by the model and the preset blood flow was $0.62 \pm 0.53 \mathrm{~L} /$ minute.

Conclusions: With variations in tidal breathing, a linear relationship exists between alveolar $\mathrm{CO}_{2}$ pressure and $\mathrm{CO}_{2}$ elimination. Existing technology may be used to calculate $\mathrm{CO}_{2}$ elimination during quiet breathing and might therefore be used to accurately calculate PBF in humans with healthy lungs.

Manuscript accepted for publication October 01, 2014

aDepartment of Anesthesia, Critical Care, and Pain Medicine, Harvard Medical School/Massachusetts General Hospital, Boston, MA, USA

${ }^{b}$ Department of Pathophysiology and Anesthesia, Nagoya City University School of Nursing, Nagoya City, Japan

${ }^{\circ}$ Department of Anesthesia, Perioperative and Pain Medicine, Harvard Medical School/Brigham and Women's Hospital, Boston, MA, USA

${ }^{\mathrm{d}}$ Corresponding Author: Richard D. Urman, Department of Anesthesiology, Critical Care and Pain Medicine, Brigham and Women's Hospital/Harvard Medical School, Boston, MA 02115, USA. Email: rurman@partners.org

doi: http://dx.doi.org/10.14740/jocmr1979w
Keywords: Pulmonary blood flow; Cardiac output; Carbon dioxide elimination; End-tidal carbon dioxide

\section{Introduction}

A clinician's ability to determine a patient's cardiac output is critical in the assessment of cardiopulmonary health. Clinically, this measurement can be required intermittently during surgery, as well as post-operatively. Cardiac output may also be measured in research settings, but doing so with invasive methods requires expensive critical care equipment, trained personnel, a sterile environment and readily available resuscitative equipment.

Cardiac output is arguably one of the most important parameters reflecting cardiovascular health and yet its measurement is currently limited to patients with Swan-Ganz catheters in the operating room, critical and intensive care units. To date, no non-invasive method has proven itself comparable to thermodilution in accuracy, repeatability, and in physiological soundness $[1,2]$. Nevertheless, the thermodilution method is plagued with limitations in clinical practice, the most important ones being associated with its invasiveness [3].

Methods for measuring cardiac output non-invasively can be classified as respiratory-based or non-respiratory-based. The latter, which includes Doppler (external, transtracheal and transesophageal), bioimpedance, and pulse contour analysis, has not yet been accepted into clinical practice because of either theoretical or practical limitations [4]. Additionally, there are some respiratory-based methods that utilize foreign gas breathing, including argon and acetylene, but these methods require a source of external gas, are impractical in many settings, and will not be dealt with in detail here [5].

The respiratory-based methods are the oldest, the most physiologically sound, and traditionally the most accepted method of cardiac output measurement. Their principles and assumptions are well understood as are their limitations, the most important of which is that they more accurately measure pulmonary blood flow (PBF) rather than cardiac output. Originally described for oxygen, Fick equation, developed in the late 1800s, is based on the measurement of elements of the mass balance across the lungs [6]. The following is the 


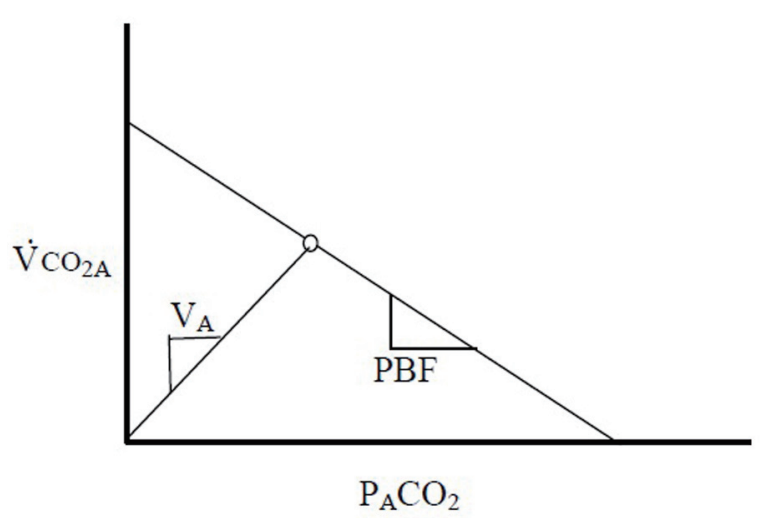

Figure 1. The relationship between $\mathrm{VCO}_{2 \mathrm{~A}}$ and $\mathrm{P}_{\mathrm{A}} \mathrm{CO}_{2}$ is linear. The slope of this line is proportional to the pulmonary blood flow. An intersecting line can be drawn from the origin following the relationship $\mathrm{V}_{\mathrm{A}}=$ $\mathrm{VCO}_{2} \times \mathrm{P}_{\mathrm{A}} \mathrm{CO}_{2} / 713$. The steady state point $(\mathrm{A})$ for $\mathrm{P}_{\mathrm{A}} \mathrm{CO}_{2}$ and $\mathrm{VCO}_{2 \mathrm{~A}}$ is produced by the balance of $\mathrm{CO}_{2}$ diffusion into the alveoli and the flow of blood into the pulmonary capillaries.

equivalent equation describing the movement of carbon dioxide $\left(\mathrm{CO}_{2}\right)$ :

Eq. 1: $\mathrm{PBF}=\mathrm{VCO}_{2} /\left(\mathrm{CvCO}_{2}-\mathrm{CaCO}_{2}\right)$

where $\mathrm{PBF}$ is the pulmonary blood flow, $\mathrm{VCO}_{2}$ is the metabolic $\mathrm{CO}_{2}$ production, and $\mathrm{CvCO}_{2}$ and $\mathrm{CaCO}_{2}$ are the concentrations of $\mathrm{CO}_{2}$ in the blood entering (mixed venous, $\mathrm{v}$ ) and leaving (arterial, a) the lungs respectively. To keep the method purely non-invasive, alveolar pressure is conventionally used as a surrogate for content. The relationship between $\mathrm{PaCO}_{2}$ and $\mathrm{CaCO}_{2}$ is usually assumed to be linear in the physiologic range, and through previous in-vitro, $\mathrm{CO}_{2}$ content of oxygenated blood can be estimated using the following equation $[7,8]$ :

Eq. 2: $\quad$ Content $=4 \times$ Pressure +260

Generally, $\mathrm{PaCO}_{2}$ is approximated from alveolar $\mathrm{CO}_{2}$ pressure $\left(\mathrm{P}_{\mathrm{A}} \mathrm{CO}_{2}\right)$, which in turn is approximated from endtidal $\mathrm{CO}_{2}$ pressure $\left(\mathrm{P}_{\mathrm{ET}} \mathrm{CO}_{2}\right)$. Mixed venous pressure of $\mathrm{CO}_{2}$ $\left(\mathrm{PvCO}_{2}\right)$ however, is difficult to obtain non-invasively, and has classically posed the biggest challenge to measurement of PBF. Respiratory maneuvers such as breathholding and rapid equilibration with external reservoirs have been employed to estimate $\mathrm{PvCO}_{2}$, but these have the disadvantage of requiring an external supply of $\mathrm{CO}_{2}$, and may pose a challenge to patients with respiratory compromise [9]. Single-breath methods have been presented, but none has proven itself repeatable and accurate.

In 1980, a novel method of calculating PBF without the need for measuring $\mathrm{CvCO}_{2}$ was described by Gedeon et al [9]. That method demonstrated that if a subject's alveolar ventilation $\left(\mathrm{V}_{\mathrm{A}}\right)$ were acutely and transiently reduced, a step change in $\mathrm{P}_{\mathrm{A}} \mathrm{CO}_{2}$ and $\mathrm{VCO}_{2}$ would result (once steady state is reached, after a few breaths). At this point, assuming $\mathrm{PBF}$ and $\mathrm{PvCO}_{2}$ had not changed in this short time $(<30-45 \mathrm{~s})$, two Fick equations could be applied to the model:

Eq. 3a: $\mathrm{PBF}=\mathrm{VCO}_{2} /\left(\mathrm{S} \times \mathrm{PvCO}_{2}-\mathrm{S} \times \mathrm{P}_{\mathrm{A}} \mathrm{CO}_{2}\right)$

Eq. 3b: $\mathrm{PBF}=\mathrm{VCO}_{2},\left(\mathrm{~S} \times \mathrm{PvCO}_{2}-\mathrm{S} \times \mathrm{P}_{\mathrm{A}} \mathrm{CO}_{2}{ }^{\prime}\right)$

where $\mathrm{VCO}_{2}$, and $\mathrm{P}_{\mathrm{A}} \mathrm{CO}_{2}$ ' are the exhaled $\mathrm{CO}_{2}$ volumes and alveolar $\mathrm{CO}_{2}$ pressures after a new steady state has oc-

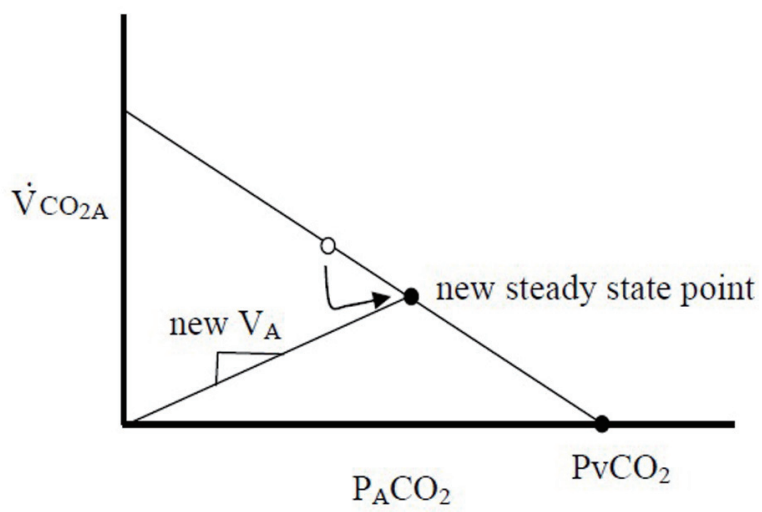

Figure 2. Gedeon's method of reducing $V_{A}$ for several breaths acutely increases $\mathrm{P}_{\mathrm{A}} \mathrm{CO}_{2}$ and reduces $\mathrm{VCO}_{2 \mathrm{~A}}$ creating a new steady state point on the same line. Point $A$ and point $B$ can be used together to calculate the slope of the line, which is the pulmonary blood flow.

curred, respectively, and $\mathrm{S}$ is a conversion constant to content. Since $\mathrm{PvCO}_{2}$ and $\mathrm{PBF}$ remain unchanged with this maneuver, these equations together yield a single equation:

Eq. 4: $\mathrm{PBF}=\left(\mathrm{VCO}_{2}-\mathrm{VCO}_{2}{ }^{\prime}\right) /\left(\mathrm{S} \times \mathrm{P}_{\mathrm{A}} \mathrm{CO}_{2}{ }^{\prime}-\mathrm{S} \times \mathrm{P}_{\mathrm{A}} \mathrm{CO}_{2}\right)$

This way, a small, temporary change in $\mathrm{V}_{\mathrm{A}}$ can be used to calculate PBF without the need for invasive monitors. This method has been proven reliable in intubated patients by multiple studies [10-12].

Creative as this method is; however, there are several limitations to it. First, the time to reach the new steady state is a function of the subject's $\mathrm{V}_{\mathrm{A}}$ and functional residual capacity (FRC). On average, this time is approximately $30-45 \mathrm{~s}$, or about five breaths, which means that only two data points are used to calculate PBF before recirculation of arterial blood occurs, limiting the method's accuracy. Second, because $V_{A}$ is required to be transiently reduced, and because the normal variability of breathing creates noise in the measurement signal, this method is limited only to intubated patients. Finally, $\mathrm{P}_{\mathrm{A}} \mathrm{CO}_{2}$ must be allowed to re-equilibrate to steady state levels before a subsequent test can be performed, which may require an additional $60-120 \mathrm{~s}$.

\section{Materials and Methods}

\section{Flux of $\mathrm{CO}_{2}$ at the alveoli}

The method proposed here redefines the term $\mathrm{VCO}_{2}$ as described in Fick's equation. According to conventional understanding, $\mathrm{VCO}_{2}$ is defined as the excretion of $\mathrm{CO}_{2}$ past the lips, measured with a pneumotachometer and $\mathrm{CO}_{2}$ monitor. However, exhaled $\mathrm{CO}_{2}$ on a breath-by-breath basis seldom reflects actual metabolic $\mathrm{CO}_{2}$ production or pulmonary capillary excretion into the lungs [13]. Instead, an average over several breaths is required for this estimation, as the FRC acts as a reservoir for $\mathrm{CO}_{2}$. For example, a large breath that expunges a large volume of $\mathrm{CO}_{2}$ past the lips would incorrectly reflect a large "production" of $\mathrm{CO}_{2}$. The Fick equation, therefore, 
Table 1. The Parameters Used in the Mathematical Model

\begin{tabular}{lll}
\hline Parameter & Error & Value \\
\hline $\mathrm{PvCO}_{2}(\mathrm{~mm} \mathrm{Hg})$ & None & 50 \\
Pulmonary blood flow (L/min) & None & 6 \\
Tidal volume $(\mathrm{mL})$ & $\pm 30 \%$ & 500 \\
Respiratory frequency $(/ \mathrm{min})$ & None & 12 \\
FRC $(\mathrm{L})$ & None & 3 \\
PBF-preset $(\mathrm{L} / \mathrm{min})$ & None & 6 \\
\hline
\end{tabular}

would be more physiologically accurate if the term $\mathrm{VCO}_{2}$ represented the continuous flux of $\mathrm{CO}_{2}$ from the blood into the alveoli $\left(\mathrm{VCO}_{2 \mathrm{~A}}\right)$, rather than the discrete, tidal excretion of $\mathrm{CO}_{2}$ past the lips $\left(\mathrm{VCO}_{2 \mathrm{M}}\right)$. Averaged over many breaths, $\mathrm{VCO}_{2 \mathrm{M}}$ will accurately reflect $\mathrm{VCO}_{2 \mathrm{~A}}$.

\section{Relationship between $\mathrm{VCO}_{2 \mathrm{~A}}$ and $\mathrm{P}_{\mathrm{A}} \mathrm{CO}_{2}$}

After redefining $\mathrm{VCO}_{2}$ in this manner, it becomes clear that there exists a linear relationship between the flux of $\mathrm{CO}_{2}$ out of the blood $\left(\mathrm{VCO}_{2 \mathrm{~A}}\right)$ and $\mathrm{P}_{\mathrm{A}} \mathrm{CO}_{2}$ (Fig. 1).

At steady state $\mathrm{VCO}_{2 \mathrm{~A}}$ and $\mathrm{P}_{\mathrm{A}} \mathrm{CO}_{2}$ produce a single point on this line. The slope of this line, $\mathrm{PBF}$, is proportional to the PBF. A second theoretical line exists on this diagram, connecting the origin with the steady state point. This second line is described by the basic physiologic equation:

Eq. 5: $\quad \mathrm{VCO}_{2 \mathrm{~A}}=\mathrm{V}_{\mathrm{A}} \times \mathrm{P}_{\mathrm{A}} \mathrm{CO}_{2} / 713$

where $\mathrm{V}_{\mathrm{A}}$ is the alveolar ventilation - the slope of the line. It becomes clear that $\mathrm{VCO}_{2 \mathrm{~A}}$ - not $\mathrm{VCO}_{2 \mathrm{M}}$ - must be applied when describing these relationships, as washout of the FRC can confound the changes that relate these variables.

Gedeon's method aims to use two steady state $\mathrm{VCO}_{2 \mathrm{M}}$ points to determine the slope of the PBF line: one attained from the subject breathing at rest (where $\mathrm{VCO}_{2 \mathrm{M}}$ only equals $\mathrm{VCO}_{2 \mathrm{~A}}$ if averaged over many breaths), and the second after a small change in $\mathrm{V}_{\mathrm{A}}$ (measured after 4 - 5 breaths, when, after a transient period, $\mathrm{VCO}_{2 \mathrm{M}}$ is assumed to be equal to $\mathrm{VCO}_{2 \mathrm{~A}}$ ). In an extreme case, if the breath were held for $30 \mathrm{~s}$ and a new steady state were reached, $\mathrm{P}_{\mathrm{A}} \mathrm{CO}_{2}$ would be equal to $\mathrm{PvCO}_{2}$, or the $\mathrm{x}$-intercept (Fig. 2). This method can only measure two points because after $4-5$ breaths of breathing at a second $\mathrm{V}_{\mathrm{A}}$, recirculation would alter $\mathrm{PvCO}_{2}$. However, if $\mathrm{VCO}_{2 \mathrm{~A}}$ can be measured with each breath, one data point along this line could be produced with each exhalation, and the slope, PBF could be calculated with sequential breaths. Variations in $\mathrm{VCO}_{2 \mathrm{~A}}$ are needed to explore this line, and the slope of the second line, $\mathrm{V}_{\mathrm{A}}$, would vary with each breath due to normal variations in tidal volume and respiratory frequency. Since $\mathrm{VCO}_{2 \mathrm{~A}}$ likely fluctuates little during quiet breathing (as opposed to $\mathrm{VCO}_{2 \mathrm{M}}$ ), variability of breathing, which was once the system "noise", therefore becomes important for measurement of PBF.

Once this line is observed over multiple breaths, PBF can be calculated by extrapolating to the $\mathrm{x}$-intercept, $\mathrm{PvCO}_{2}$, and calculating PBF using equation 1.

\section{Method for calculating $\mathrm{VCO}_{2 \mathrm{~A}}$}

The method described above requires calculation of the $\mathrm{VCO}_{2 \mathrm{~A}}$, the flux of $\mathrm{CO}_{2}$ across the alveolar membrane. Calculation for $\mathrm{VCO}_{2 \mathrm{~A}}$ has been described thoroughly elsewhere [13]. Briefly, a simple mass balance dictates that the flux of $\mathrm{CO}_{2}$ into the alveoli from the blood is related to the flux of $\mathrm{CO}_{2}$ at the mouth and the change of $\mathrm{CO}_{2}$ stores in the lung:

Eq. 6: $\mathrm{VCO}_{2 \mathrm{~A}}=\mathrm{VCO}_{2 \mathrm{M}}-\Delta \mathrm{VCO}_{2 \mathrm{~S}}$

where $\mathrm{VCO}_{2 \mathrm{~A}}$ is the alveolar flux of $\mathrm{CO}_{2}, \mathrm{VCO}_{2 \mathrm{M}}$ is the flux of $\mathrm{CO}_{2}$ at the mouth, and $\Delta \mathrm{VCO}_{2 \mathrm{~S}}$ is the change in lung stores of $\mathrm{CO}_{2} . \mathrm{VCO}_{2 \mathrm{M}}$ is easily measured using a metabolic cart, which integrates exhaled $\mathrm{CO}_{2}$ concentration and expiratory flow.

The change in lung stores of $\mathrm{CO}_{2}$ from breath 1 to breath 2, $\Delta \mathrm{VCO}_{2 \mathrm{~S}}$, can be described as the sum of two terms describing the change in $\mathrm{CO}_{2}$ concentration at a constant $\mathrm{V}_{\mathrm{A}}$, and the change in $\mathrm{V}_{\mathrm{A}}$ at a constant $\mathrm{CO}_{2}$ concentration:

Eq. 7: $\Delta \mathrm{VCO}_{2 \mathrm{~S}}=\mathrm{V}_{\mathrm{A}}\left(\mathrm{P}_{\mathrm{A}} \mathrm{CO}_{2}{ }^{\prime}-\mathrm{P}_{\mathrm{A}} \mathrm{CO}_{2}\right) / 713+\mathrm{P}_{\mathrm{A}} \mathrm{CO}_{2}{ }^{\prime} \Delta \mathrm{V}_{\mathrm{A}}$

where $\triangle \mathrm{VCO}_{2 \mathrm{~S}}$ is the change in alveolar stores of $\mathrm{CO}_{2}$, $\mathrm{V}_{\mathrm{A}, 1}$ is the alveolar volume at the end of breath $1, \mathrm{P}_{\mathrm{A}} \mathrm{CO}_{2}$ and $\mathrm{P}_{\mathrm{A}} \mathrm{CO}_{2}$, are the fractions of $\mathrm{CO}_{2}$ in the alveoli at the end of breaths 1 and 2, respectively and $\Delta \mathrm{V}_{\mathrm{A}}$ is the change in alveolar volume from breath 1 to breath 2 .

\section{Computer simulation}

For this study, a computer simulation of tidal breathing was designed to test the theory under ideal conditions using Microsoft Excel 2003 (Redmond, Washington, USA). Incremental calculations of lung $\mathrm{CO}_{2}$ volume were made for each 0.001 min. Tidal breathing was simulated using variable inhaled and exhaled tidal volumes $( \pm 30 \%)$, allowing lung volume to return to a different FRC with each breath. Complete alveolar mixing was assumed, inspiratory and expiratory times were equal, inhalation and exhalation flows were linear, and alveolar dead-space and shunt were assumed to be minimal. $\mathrm{P}_{\mathrm{A}} \mathrm{CO}_{2}$ was recorded once per breath (the final $\mathrm{P}_{\mathrm{A}} \mathrm{CO}_{2}$ value at the end of exhalation) and $\mathrm{VCO}_{2 \mathrm{M}}$ was calculated at the mouth during exhalation. The model was run over a period of $10 \min (100$ breaths), and $\mathrm{P}_{\mathrm{A}} \mathrm{CO}_{2}, \mathrm{VCO}_{2 \mathrm{M}}$, Vt-in and Vt-out were recorded with each breath. $\mathrm{V}_{\mathrm{A}}$ for sequential breaths was calculated as $\mathrm{V}_{\mathrm{A}}{ }^{\prime}=\mathrm{V}_{\mathrm{A}}+\mathrm{Vt}$-in - Vt-out, where Vt-in and Vt-out are inhaled tidal volume and exhaled tidal volume, respectively. Detailed parameters are outlined in Table 1.

\section{$\mathrm{P}_{\mathrm{A}} \mathrm{CO}_{2}$-ave versus $\mathrm{P}_{\mathrm{ET}} \mathrm{CO}_{2}$}

As stated above, the diffusion of $\mathrm{CO}_{2}$ across the alveolar membrane should form a linear relationship with the pressure of $\mathrm{CO}_{2}$ in the alveoli. Therefore, measurements of $\mathrm{P}_{\mathrm{ET}} \mathrm{CO}_{2}$, a single sample taken at the end of exhalation, would be inappropriate to use in equation 3 since it reflects an end-expiration value rather than an average $\left(\mathrm{P}_{\mathrm{A}} \mathrm{CO}_{2}\right.$-ave $)$. In the computer model, an average $\mathrm{P}_{\mathrm{A}} \mathrm{CO}_{2}$ is easy to calculate, but this is not the case clinically, when $\mathrm{P}_{\mathrm{ET}} \mathrm{CO}_{2}$ samples are the only measurements 


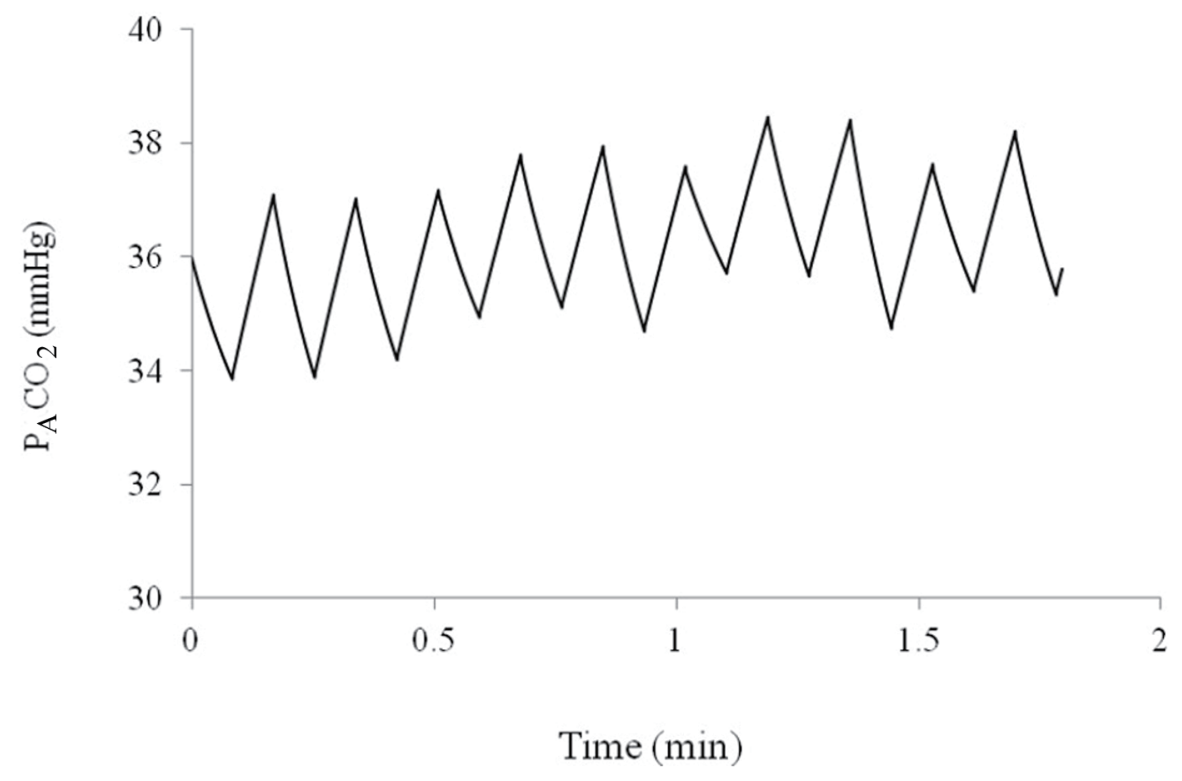

Figure 3. Alveolar partial pressure of $\mathrm{CO}_{2}$ over a period of $2 \mathrm{~min}$ as predicted by the computer model.

readily available non-invasively. To estimate $\mathrm{P}_{\mathrm{A}} \mathrm{CO}_{2}$-ave for a single breath using only non-invasive data, we back-calculated to the $\mathrm{P}_{\mathrm{A}} \mathrm{CO}_{2}$ that might exist at peak inhalation and averaged this with $\mathrm{P}_{\mathrm{ET}} \mathrm{CO}_{2}$. The $\mathrm{P}_{\mathrm{A}} \mathrm{CO}_{2}$ at peak inhalation might be estimated as:

Eq. 8: (Volume of $\mathrm{CO}_{2}$ in Lung at End-Exhalation - Volume of $\mathrm{CO}_{2}$ Diffused during Exhalation + Exhaled Volume of $\left.\mathrm{CO}_{2}\right) \times 713 /$ Peak Alveolar Volume

Averaging this value with $\mathrm{P}_{\mathrm{ET}} \mathrm{CO}_{2}$ may produce a reasonable estimate of $\mathrm{P}_{\mathrm{A}} \mathrm{CO}_{2}$-ave which can be applied in equation 1 .

\section{Calculation of $\mathrm{VCO}_{2 \mathrm{~A}}$}

$\mathrm{VCO}_{2 \mathrm{~S}}$ was calculated using equation 6 using sequential breaths, $\Delta \mathrm{V}_{\mathrm{A}}$ was assumed to be measurable without the need for nitrogen monitors (Vt-in and Vt-out were measurable), and VA was initially assumed to be $3 \mathrm{~L}$. $\mathrm{VCO}_{2 \mathrm{~A}}$ was then calculated using equation 5 . Using $10 \mathrm{~min}$ of breathing data, when $\mathrm{PBF}$ and $\mathrm{PvCO}_{2}$ were assumed to be in steady state, a plot of $\mathrm{VCO}_{2 \mathrm{~A}}$ versus $\mathrm{P}_{\mathrm{A}} \mathrm{CO}_{2}$ was created and $\mathrm{R}^{2}$ was calculated for

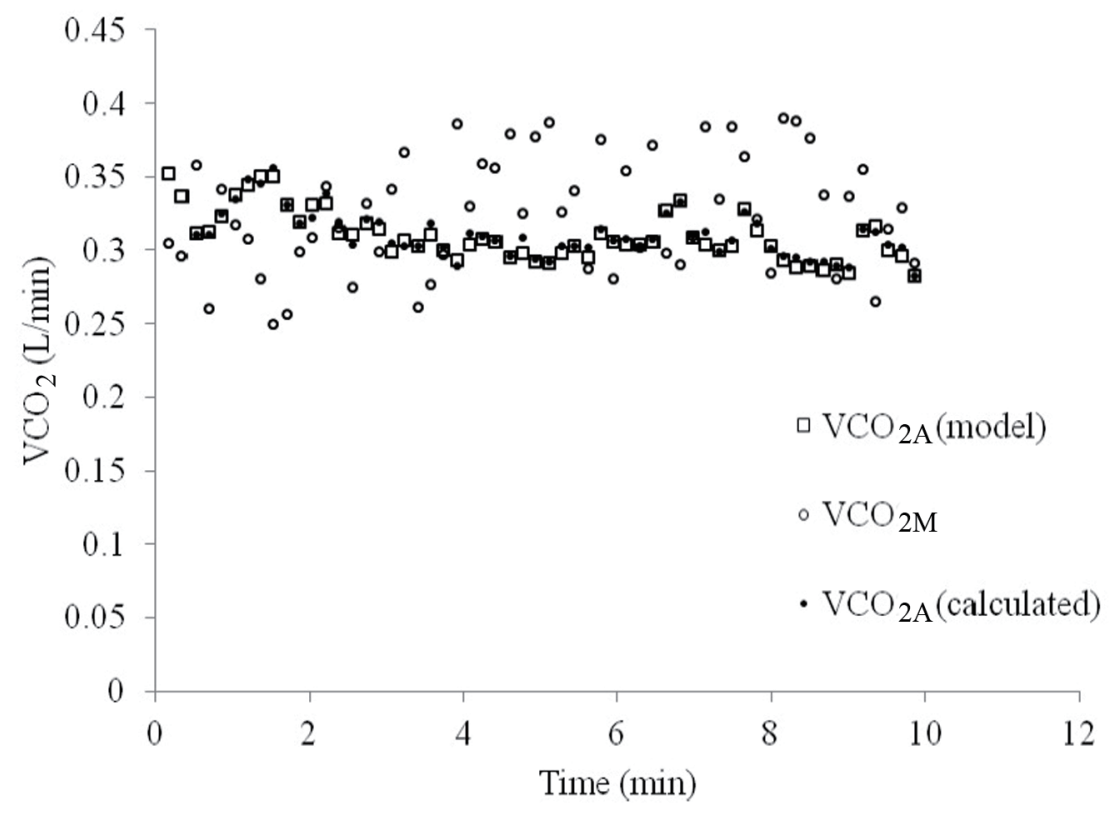

Figure 4. $\mathrm{VCO}_{2}$ over time as measured at the mouth $\left(\mathrm{VCO}_{2 \mathrm{M}}\right.$, open circles), as pre-set by the model $\left(\mathrm{VCO}_{2 \mathrm{~A}}-\mathrm{model}_{\text {, open }}\right.$ squares) and as calculated using the proposed method $\left(\mathrm{VCO}_{2 \mathrm{~A}}\right.$-calculated, closed circles). 


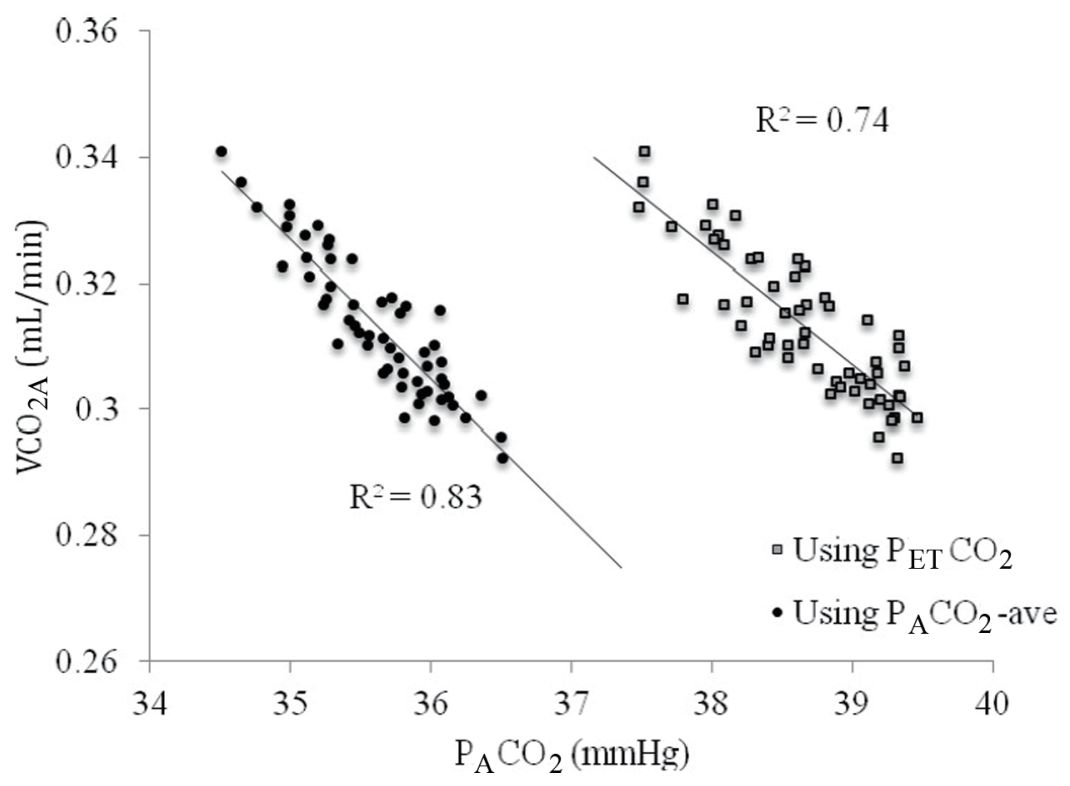

Figure 5. The relationship between $\mathrm{VCO}_{2 A}$ and $\mathrm{P}_{A} \mathrm{CO}_{2}$ using end-tidal $\mathrm{PCO}_{2}\left(\mathrm{P}_{E T} \mathrm{CO}_{2}\right.$, gray squares) versus time averaged $\mathrm{CO}_{2}$ across the breath $\left(\mathrm{P}_{\mathrm{A}} \mathrm{CO}_{2}\right.$-ave, closed circles).

the line of best fit. FRC was then iterated in increments of 0.25 $\mathrm{L}$ from $2 \mathrm{~L}$ to $4 \mathrm{~L}$ to achieve the most optimal linear relationship between $\mathrm{VCO}_{2 \mathrm{~A}}$ and $\mathrm{P}_{\mathrm{A}} \mathrm{CO}_{2}$.

\section{Real-world adjustments}

To simulate real-world measurements, error was introduced into each measurement $\left(\mathrm{P}_{\mathrm{A}} \mathrm{CO}_{2}, \mathrm{Vt}\right.$-in, Vt-out, $\mathrm{VCO}_{2 \mathrm{M}}$, Table 1), consistent with manufacturer specifications [14] and calculation of PBF was repeated.

\section{PBF comparisons}

PBF was calculated from equation 3 using two techniques: first, using known $\mathrm{VCO}_{2 \mathrm{~A}}$ measurements directly from the model (PBF-preset), calculated using actual diffusion of $\mathrm{CO}_{2}$ across the alveolar membrane, and second, using $\mathrm{VCO}_{2 \mathrm{M}}$ to calculate $\mathrm{VCO}_{2 \mathrm{~A}}$ using equation 5 (PBF-calc), which represents the strategy that might be used practically in subjects. In the either case, PBF would be calculated using equation 1 where $\mathrm{PvCO}_{2}$ was attained by extrapolating to the $\mathrm{x}$-intercept of a plot relating $\mathrm{VCO}_{2 \mathrm{~A}}$ and $\mathrm{P}_{\mathrm{A}} \mathrm{CO}_{2}$-ave. We determined the appropriate number of breaths required for accurate measurement of PBF-calc, by increasing the number of breaths used to calculate the average PBF-calc until the repeatability was similar to that of thermodilution [15].

PBF-calc was assessed and evaluated using Bland-Altman analysis where the acceptable error was taken from prior established theory [16].

\section{Results}

The model for tidal ventilation produces reasonable values for $\mathrm{P}_{\mathrm{A}} \mathrm{CO}_{2}$ over 10 min of breathing. Sample oscillations in $\mathrm{P}_{\mathrm{A}} \mathrm{CO}_{2}$ and lung volume can be seen in Figure 3.

$\mathrm{VCO}_{2 \mathrm{~A}}$ tended to vary less over the course of $10 \mathrm{~min}$ of breathing than $\mathrm{VCO}_{2 \mathrm{M}}$, as can be seen in Figure 4. When $\mathrm{VCO}_{2 \mathrm{~A}}$ was plotted against $\mathrm{P}_{\mathrm{A}} \mathrm{CO}_{2}$-ave a linear relationship was revealed which was stronger than with $\mathrm{P}_{\mathrm{ET}} \mathrm{CO}_{2}(\mathrm{R}=0.83$ versus 0.74 , Fig. 5).

Iterating FRC demonstrated that small deviations from the model value produced poorer relationships between $\mathrm{VCO}_{2 \mathrm{~A}}$ and $\mathrm{P}_{\mathrm{A}} \mathrm{CO}_{2}$ (Fig. 6). However, the optimal FRC achieved after iterating FRC was $3.25 \mathrm{~L}$, which was $0.25 \mathrm{~L}(8.3 \%)$ greater than the actual FRC used in the model. Non-optimal FRCs did not significantly reduce the accuracy of the calculated PBF, but did increase its variability.

When $\mathrm{P}_{\mathrm{A}} \mathrm{CO}_{2}$-ave was used instead of $\mathrm{P}_{\mathrm{ET}} \mathrm{CO}_{2}$, the relationship was improved $\left(\mathrm{R}^{2}=0.83\right.$ versus 0.74$)$. PBF-calc was calculated using 10 breaths at a time (see repeatability below) by extrapolating the line in Figure 3 to the $\mathrm{x}$-intercept $\left(\mathrm{PvCO}_{2}\right)$ and applied into equation 1 . Using this method, the difference between PBF-preset and PBF-calc was $0.62 \pm 0.53 \mathrm{~L} / \mathrm{min}$.

Figure 7 shows that the repeatability coefficient fell from 1.13 to $0.09 \mathrm{~L} / \mathrm{min}$ as the number of breaths used to calculate PBF-calc increased from 2 to 30 . The repeatability coefficient decreased and leveled at 0.09 when approximately 10 breaths were used to average calculation for PBF-calc. The repeatability coefficient for thermodilution is likely between 0.4 and 0.6 $\mathrm{L} / \mathrm{min}[4,15]$ ), which is the equivalent of using 5 - 6 breaths to average PBF-calc measurements in the proposed method. 


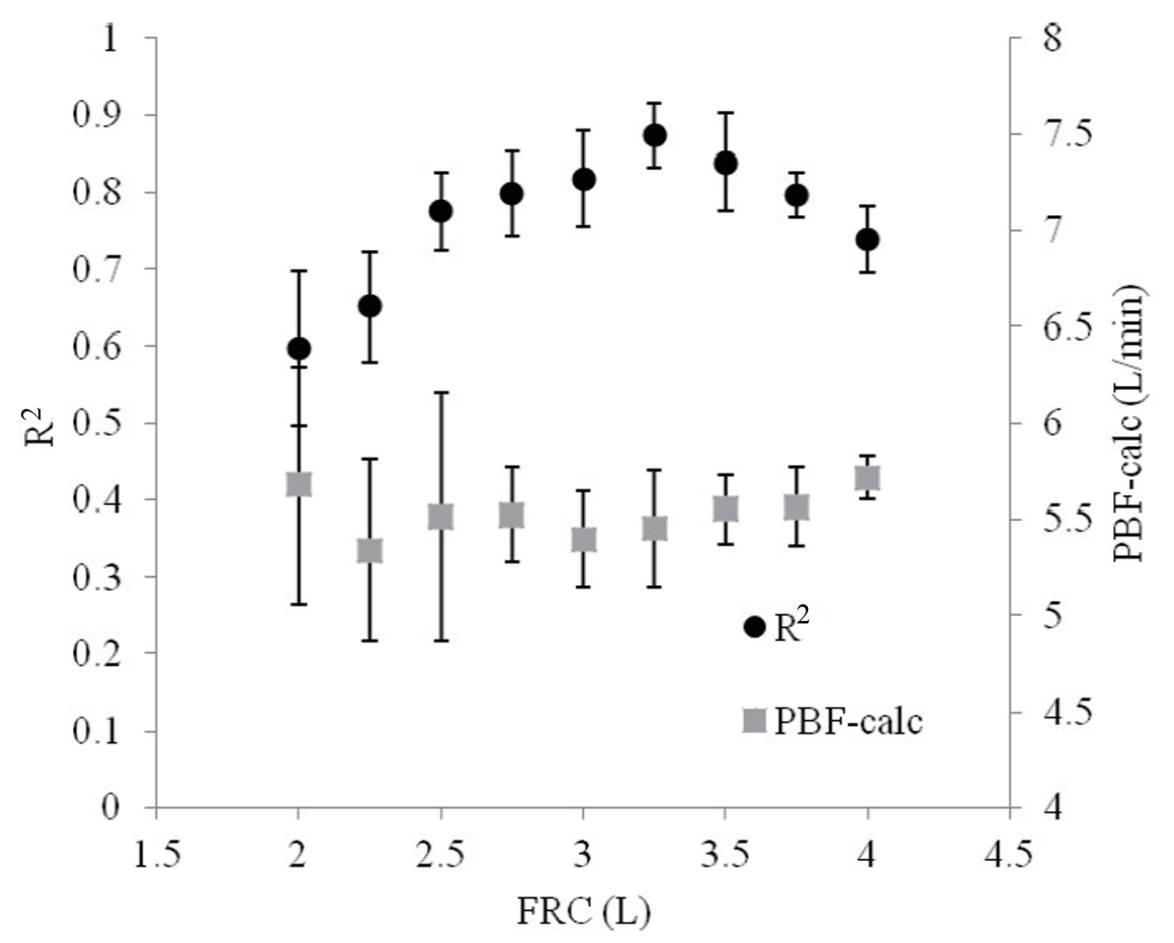

Figure 6. The $R^{2}$ statistical parameter relating $V_{C O}$ to $P_{A} C O_{2}$ varies depending on the original estimate of $F R C$. As the initial guess of $F R C$ is increased, $R^{2}$ reaches a peak, optimum point and then falls.

\section{Discussion}

The most common method for cardiac output measurement involves indicator dilution, normally dyes and temperature. A dye, or cold saline, is typically injected via an invasive catheter into the pulmonary artery and the temporal profile of the concentration of the dye or the temperature of the blood is measured downstream. The profile of the indicator change over time is used to calculate the cardiac output. Over the last three decades, there has been a steady improvement in the technology required to manufacture the catheters and thermistors, and to analyze the indicator curves and calculate the cardiac output [17]. In addition, the expertise to place the catheters and look after catheterized patients has become widespread.

Nevertheless, there are at least three drawbacks necessarily associated with these methods. First, pulmonary artery catheters are inherently invasive and have associated complications including damage to the carotid artery, subclavian artery and lung, air emboli, pneumothorax, malignant arrhythmias and heart block, rupture of right atrium, right ventricle and/or pulmonary capillary, local infection and septicaemia, and more [3]. Second, they have many associated costs as a result of the requirement for critical care areas, equipment and personnel. Third, their accuracy is questionable, and can be less reliable and helpful as required for management of critically ill patients [18]. Despite these drawbacks, thermodilution methods continue to be widely used as less invasive alternatives are not sufficiently accurate, not sufficiently robust, or too cumbersome to perform in a large variety of clinical settings [19].

In this study, a new non-invasive method of measuring
PBF is introduced based on principles that are already accepted in medicine. The Fick method for measuring PBF is well established and is considered one of the most accurate techniques available. Until recently, however, the Fick technique could only be performed using blood samples despite numerous attempts to measure $\mathrm{PvCO}_{2}$ non-invasively. The method of creating a step-change in $\mathrm{V}_{\mathrm{A}}$ is the only validated non-invasive Fick method of cardiac output measurement without a special maneuver required by the patient, but can only be used on patients ventilated by a mechanical ventilator, uses only two breaths for measurement ETC. If a spontaneously breathing patient is made to rebreathe previously exhaled gas, the minute ventilation will tend to increase in order to increase the volume of air entering the lungs for gas exchange. The method presented here would require no maneuver on the part of the subject, and no foreign or compressed gases.

The method outlined here describes an original relationship between $\mathrm{VCO}_{2}$ and $\mathrm{P}_{\mathrm{A}} \mathrm{CO}_{2}$. Its principles are grounded in basic physiology, and its application may extend beyond that of PBF measurement. Since $\mathrm{P}_{\mathrm{A}} \mathrm{CO}_{2}$ relates directly to $\mathrm{VCO}_{2}$ given a specific set of conditions, other variables that may influence these parameters such as alveolar dead space, may be measureable as well.

There are several practical limitations of this method. First, this strategy for measuring PBF could not be achieved without a perfect, air-tight seal around the mouth, nose, or face. Any air lost would reduce the accuracy of Vt-in, Vt-out, or $\mathrm{VCO}_{2 \mathrm{M}}$. This may be inconvenient or impossible for some patients, depending on the presence of facial hair, anomalous anatomy, or trauma. 


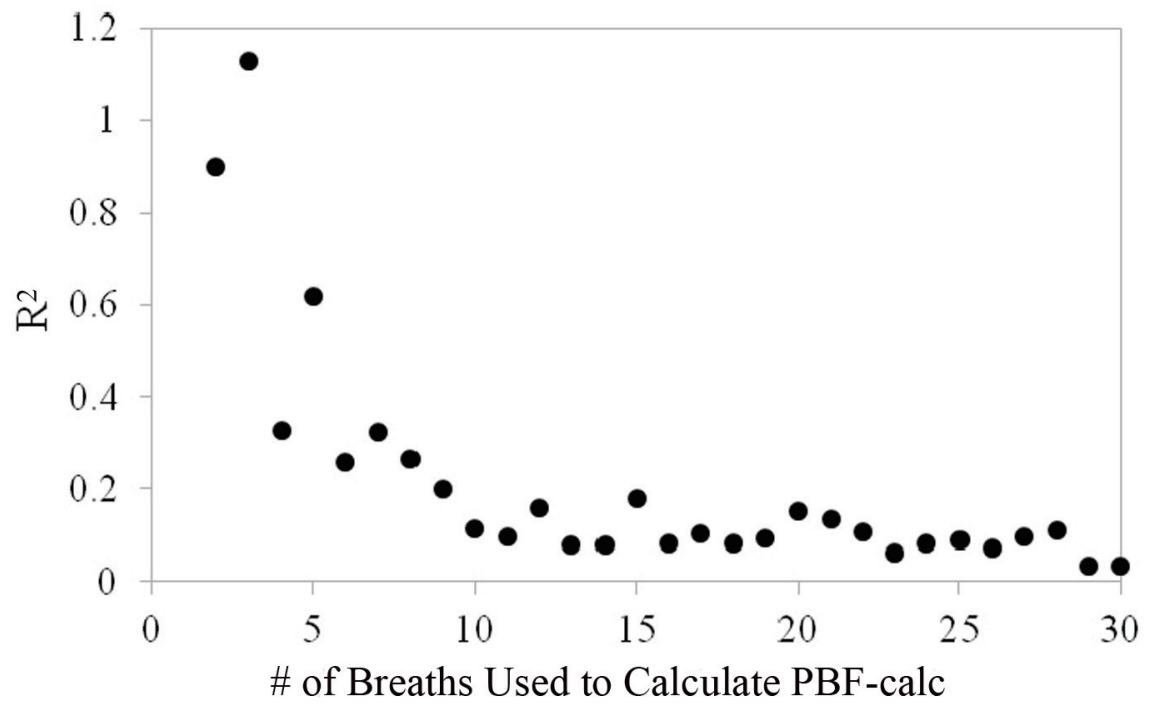

Figure 7. As few as two breaths can be used to calculate PBF but its reliability is increased as more breaths are incorporated into the calculation. Precision reaches a plateau at about $8-10$ breaths.

This model assumes that all exhaled gas had participated in exchange of $\mathrm{CO}_{2}$ with the blood. $\mathrm{P}_{\mathrm{A}} \mathrm{CO}_{2}$ may vary depending on differences in ventilation-to-perfusion matching throughout the lung $[2,20]$. If some exhaled gas originated from alveolar dead space, $\mathrm{P}_{\mathrm{ET}} \mathrm{CO}_{2}$ would underestimate $\mathrm{P}_{\mathrm{A}} \mathrm{CO}_{2}$ and as a result, PBF-calc would overestimate PBF. The significance of this was not quantified in this study, but theoretically, it is possible that iterations of alveolar dead space estimates can be coupled with the estimates of FRC to provide an optimal relationship between $\mathrm{P}_{\mathrm{A}} \mathrm{CO}_{2}$ and $\mathrm{VCO}_{2 \mathrm{~A}}$. Still, deviations of $\mathrm{P}_{\mathrm{ET}} \mathrm{CO}_{2}$ from $\mathrm{P}_{\mathrm{A}} \mathrm{CO}_{2}$ may also be due to incomplete breaths during exhalation and not alveolar deap space per se. This also impacts the calculation for $\mathrm{P}_{\mathrm{A}} \mathrm{CO}_{2}$-ave, which will also be affected by all of the above.

In this study, 10 min of breathing were permitted to achieve initial FRC estimate. At this point, it is unclear why the ideal FRC produced from the iterative process differed from that used in the model. Nevertheless, its impact on PBF-calc was marginal. Furthermore, the purpose of this extended period of breathing was to demonstrate the principle rather than practicality. Follow-up studies in humans will be required to further explore this strategy.

The real-world error in measuring $\mathrm{Vt}, \mathrm{P}_{\mathrm{ET}} \mathrm{CO}_{2}, \mathrm{VCO}_{2}$ was based on products currently available for purchase. These will vary depending on the manufacturer and may improve in the future, making this method more practical.

The accuracy of this method for measuring PBF was similar to others that have been proposed [15]. The repeatability demonstrated that 10 breaths were needed for optimal accuracy, a time slightly greater than would be required for a complete test of thermodilution (about $30 \mathrm{~s}$ ) depending on respiratory frequency. However, one advantage of the proposed method in this respect is that measurements for PBF are continuous, and no time is needed for "reset", as may be needed to washout indicator from the pulmonary artery for thermodilution.
Finally, whereas the accuracy of other respiratory-based non-invasive methods may be diminished by respiratory fluctuations, the proposed method is enhanced by large changes in tidal volume and respiratory frequency. It may even be suggested that a subject ought to be encouraged to take deep breaths, or sigh to exaggerate the variability of quiet tidal breathing.

\section{Conclusion}

The study we describe here is safe, theoretically sound, and demonstrates acceptable accuracy and repeatability. It represents a potential advancement towards measurement of important cardiopulmonary parameters that may be clinically important in the management of both outpatients and those in-hospital. Further studies in humans are required to quantify and evaluate its strengths and limitations.

\section{Acknowledgement}

None.

\section{Conflict of Interest}

The authors report no conflicts of interest.

\section{Source(s) of Support}

Funding for this study was provided by internal department 
funds.

\section{References}

1. Branthwaite MA, Bradley RD. Measurement of cardiac output by thermal dilution in man. J Appl Physiol. 1968;24(3):434-438.

2. Kim TS, Rahn H, Farhi LE. Estimation of True Venous and Arterial Pco2 and Cardiac Output by Gas Analysis of a Single Breath. Techn Docum Rep Amrl-Tdr-63-103 (I). AMRL TR. 1963:58-73.

3. Nadeau S, Noble WH. Limitations of cardiac output measurements by thermodilution. Can Anaesth Soc J. 1986;33(6):780-784.

4. Wong LS, Yong BH, Young KK, Lau LS, Cheng KL, Man JS, Irwin MG. Comparison of the USCOM ultrasound cardiac output monitor with pulmonary artery catheter thermodilution in patients undergoing liver transplantation. Liver Transpl. 2008;14(7):1038-1043.

5. Wendelboe Nielsen O, Hansen S, Christensen P, Gronlund J. Repeatability of the acetylene rebreathing method in measuring cardiac output: influence of acetylene concentration. Acta Anaesthesiol Scand. 1990;34(5):354357.

6. Fick A. Ueber die Messung des Blutquantums in den Herzventrikeln. Sitzungsberichte der Physiologisch Medizinosche Gesellschaft zu Wuerzburg.2.

7. Levett JM, Replogle RL. Thermodilution cardiac output: a critical analysis and review of the literature. J Surg Res. 1979;27(6):392-404.

8. Olszowka AJ, Farhi LE. A system of digital computer subroutines for blood gas calculations. Respir Physiol. 1968;4(2):270-280.

9. Gedeon A, Forslund L, Hedenstierna G, Romano E. A new method for noninvasive bedside determination of pulmonary blood flow. Med Biol Eng Comput. 1980;18(4):411418.
10. Bosman RJ, Stoutenbeek CP, Zandstra DF. Non-invasive pulmonary blood flow measurement by means of $\mathrm{CO} 2$ analysis of expiratory gases. Intensive Care Med. 1991;17(2):98-102.

11. Capek JM, Roy RJ. Noninvasive measurement of cardiac output using partial $\mathrm{CO} 2$ rebreathing. IEEE Trans Biomed Eng. 1988;35(9):653-661.

12. Peyton PJ, Thompson D, Junor P. Non-invasive automated measurement of cardiac output during stable cardiac surgery using a fully integrated differential $\mathrm{CO}(2)$ Fick method. J Clin Monit Comput. 2008;22(4):285-292.

13. Auchincloss JH, Jr., Gilbert R, Baule GH. Effect of ventilation on oxygen transfer during early exercise. J Appl Physiol. 1966;21(3):810-818.

14. CareFusion I. Manufacturer Specifications. Vmax System Specifications. http://www.carefusion.com/pdf/Respiratory/Pulmonary_Function_Testing/RC1355-01_VmaxSpecsheet10.pdf. 2013.

15. Critchley LA, Critchley JA. A meta-analysis of studies using bias and precision statistics to compare cardiac output measurement techniques. J Clin Monit Comput. 1999;15(2):85-91.

16. Bland JM, Altman DG. Statistical methods for assessing agreement between two methods of clinical measurement. Lancet. 1986;1(8476):307-310.

17. Lenfant C. Time-dependent variations of pulmonary gas exchange in normal man at rest. J Appl Physiol. 1967;22(4):675-684.

18. Nishikawa T, Dohi S. Errors in the measurement of cardiac output by thermodilution. Can J Anaesth. 1993;40(2):142-153.

19. Stetz CW, Miller RG, Kelly GE, Raffin TA. Reliability of the thermodilution method in the determination of cardiac output in clinical practice. Am Rev Respir Dis. 1982;126(6):1001-1004.

20. Dubois $\mathrm{AB}$. Alveolar $\mathrm{CO} 2$ and $\mathrm{O} 2$ during breath holding, expiration, and inspiration. J Appl Physiol. 1952;5(1):112. 